\title{
Horizontal Inequity in Access to Health Care in Four South American Cities*
}

\author{
Received: February, 2011 - Accepted: March, 2011
}

\begin{abstract}
Ana I. Balsa ${ }^{\dagger}$
Universidad de Montevideo.

Máximo Rossi ${ }^{\ddagger}$

Departamento de Economía.

Universidad de la República.

Patricia Triunfo ${ }^{\S}$
Departamento de Economía.
Universidad de la República.
\end{abstract}

Centro de investigaciones Aplicadas, Departamento de Economía.

\section{Resumen}

El objetivo de este trabajo es analizar el grado de inequidad socioeconómica en el uso de servicios médicos de la población adulta mayor en cinco ciudades latinoamericanas (Buenos Aires, Ciudad de México, Santiago de Chile, San Pablo y Montevideo), en base a los datos de la Encuesta de Salud, Bienestar y Envejecimiento relevada entre 1999 y 2000 (SABE, OPS/OMS, 2001). El análisis imputa el ingreso equivalente del hogar a través de la utilización de las encuestas de hogares de los distintos países, y considerando una amplia serie de indicadores de acceso, calidad y uso de servicios de salud. Una vez estandarizado el uso de servicios por las necesidades de cuidados, se encuentran desigualdades socioeconómicas pro-rico en el uso de servicios preventivos en todas las ciudades, desigualdades en la realización de visitas médicas en Santiago y Montevideo, y desigualdades en la calidad de acceso a la atención en todas las ciudades salvo Montevideo. Las desigualdades socioeconómicas dentro de los sistemas de salud públicos o privados explican una mayor proporción de las desigualdades en el acceso a la atención. Nuestros resultados son informativos en el contexto de las políticas recientes destinadas a la aplicación de paquetes mínimos

*We are grateful to Daniel Ferrés, Juan Pablo Pagano, and Eugenia Rivas for valuable assistance and contributions to this study. The data used in this study are publicly available through the Inter-University Consortium for Political and Social Research. In preparing the data files for public archiving and distribution, the data producers removed all direct identifiers and characteristics that might lead to identification of data subjects. Because of the public nature of these data, no approval by any committee for the protection of human subjects was sought or awarded.

${ }^{\dagger}$ Centro de Investigaciones Aplicadas, Departamento de Economía. Universidad de Montevideo, Montevideo, Uruguay. Correo electrónico: abalsa@um.edu.uy

${ }^{\ddagger}$ Departamento de Economía, Facultad de Ciencias Sociales. Universidad de la República, Montevideo, Uruguay. Correo electrónico: mito@decon.edu.uy

$\S^{\S}$ Departamento de Economía, Facultad de Ciencias Sociales. Universidad de la República, Montevideo, Uruguay. Correo electrónico: patricia@decon.edu.auy

(C) Revista de Economía del Rosario. Universidad del Rosario. 
de servicios.

Clasificación JEL: I1, I11, I12, I18.

Palabras clave: Desigualdad horizontal, acceso al sistema de salud, Suramérica.

\begin{abstract}
The objective of this paper is compare socioeconomic inequalities in the use of healthcare services in four South-American cities: Buenos Aires, Santiago, Montevideo, and San Pablo. We use secondary data from SABE, a survey on Health, Well-being and Aging administered in 2000 under the sponsorship of the Panamerican Health Organization, and representative of the elderly population in each of the analyzed cities. We construct concentration indices of access to and quality of healthcare services, and decompose them in socioeconomic, need, and non-need contributors. We assess the weight of each contributor to the overall index and compare indices across cities. Our results show high levels of pro-rich socioeconomic inequities in the use of preventive services in all cities, inequities in medical visits in Santiago and Montevideo, and inequities in quality of access to care in all cities but Montevideo. Socioeconomic inequality within private or public health systems explains a higher portion of inequalities in access to care than the fragmented nature of health systems. Our results are informative given recent policies aimed at enforcing minimum packages of services and given policies exclusively focused on defragmenting health systems.
\end{abstract}

JEL Classification: I1, I11, I12, I18.

Keywords: Horizontal inequity, health care access, South America. 


\section{Introduction}

In the past decade several South American countries introduced reforms aimed at improving equity in access to health care. In Chile, the "Plan AUGE" enforced minimum standards of service delivery for all insurance carriers. Uruguay initiated in 2008 a process towards a National Health Insurance System, and is gradually incorporating different cohorts of the population to the new scheme. Argentina's efforts have focused on strengthening primary care and decentralizing health care provision, and Brazil has continued to consolidate its public universal health system introduced in the 90's.

Research stemming from the EquiLAC project (a World Bank project with the support of Spanish and Danish governments) and the IHEP collaboration (a PAHO project funded by the United Nations) has contributed to inform some of these reform processes by quantifying and comparing inequities across a number of Latin American countries (Suárez Berenfuela, 2000; PAHO, 2002). ${ }^{1}$

In this study, we use healthcare concentration indices to shed light on this question. Using the methodology proposed by van Doorslaer et al. (2004, 2006) we measure, decompose, and compare socioeconomic inequalities in various indicators of healthcare utilization across four South American major cities: Buenos Aires (Argentina), Santiago (Chile), Sao Paulo (Brazil), and Montevideo (Uruguay). We analyze data from the WHO Survey on Health, Wellbeing and Ageing (SABE), a survey administered in 2000 to elderly adults living in major cities from Latin America and the Caribbean.

Underlying our analysis is the concept of horizontal equity in health care, which proposes equal treatment to those with equal needs. Much of the empirical literature in this area has explored the associations between the institutional organization of healthcare systems and horizontal equity in access and use (Culyer and Newhouse, 2003; Macinko and Starfield, 2002). One example is the ECuity Project, a multiyear study funded by the European Union, national governments and other organizations, aimed at analyzing health and healthcare inequities in OECD countries. Results for European countries, most of which have universal coverage health systems, found little inequity in visits to general practitioners but a concentration of specialty visits favoring high-income groups in countries where private insurance coverage or private practice options were offered as channels to quicker or preferential access (van Doorslaer et al., 2004, 2006; ?). These studies suggest that the frag-

\footnotetext{
${ }^{1}$ The EquiLAC focused on measuring health system inequalities in Brazil, Ecuador, Jamaica, and Mexico. The IHEP collaboration studied the nature of healthcare inequalities among the poorest (the lowest $20 \%$ of the income distribution) in Brazil, Ecuador, Guatemala, Jamaica, and Peru. Results from these and other Latin American studies found pro-rich inequities in visits to health professionals, ambulatory and in-hospital services, preventive care, curative services, and quality of care, among other health care services (Bertranou, 1993, 1998, 1999; Suárez Berenfuela, 2000; Noronha and Andrade, 2005; Wallace and Gutierrez, 2005; De Santis and Herrero, 2009) Still, only a few investigations have explored the weight of different contributors to inequalities in healthcare in these countries, and in particular the degree to which the mixed and fragmented nature of health insurance systems mediate the link between economic inequality and inequitable access to health care (Wallace and Gutierrez, 2005; Bertranou, 1999).
} 
mentation of healthcare systems, mostly due to the allowance of private coverage options, is the main culprit for inequality in access to care (García Gómez and López, 2004).

In Latin America, however, levels of income inequality are higher than those in Europe. While fragmented healthcare systems are probably behind the unequal access to care, high levels of inequality in access can also be expected within each delivery system (public or private). In this scenario, policy recommendations aimed only at system defragmentation can fall short of providing adequate solutions to the problem.

The contribution of this study is twofold. First, we quantify and identify, for each city, the services that make each system more inequitable, both when compared with other services in the country as across cities. Our findings regarding inequalities in preventive care are quite informative given the new shifts in policy towards primary levels of attention. Second, our decomposition analysis shows that inequities within each insurance sub-system are more important inequalizing forces than those between systems, i.e., the fragmentation of insurance systems. Factors such as copayments within the private system or socioeconomic differences in the ability of beneficiaries to make empowered decisions about health care and navigate the system seem to be more important determinants of the observed inequities.

\section{Institutional background}

The four countries under study have mixed health systems, with coexisting public and private insurers and providers. They show significant differences, however, in the nature of public and private coverage. In Brazil, the public system ("Sistema Único de Saude", Unique Health System) warrants universal coverage to all citizens. The system is based on a decentralized regional network regulated by the Ministry of Public Health and financed with public resources. Due to the regional economic disparities that characterize the country, and because federal support does not pursue redistributive goals, richer states present higher per capita health expenditure. The private system, on the other hand, is a fragmented conjunction of plans that include prepaid group practices, medical cooperatives, employer provided insurance, and indemnity plans. Approximately $75 \%$ of the population is exclusively covered by public health insurance. The rate is lower in the city of Sao Paulo because of its higher levels of income (62\% according to SABE estimates). Although everyone has the right to use the public system, those with private coverage are unlikely to make use of it, except for high cost procedures, such as cancer treatment, which are generally not covered by private insurers.

In Chile, public coverage is provided through the National Health Fund (FONASA), while the ISAPRES ("Instituciones de Salud Previsional" or Social Security Health Institutions) are the institutions in charge of offering private insurance. Contributors to social security can choose whether to receive coverage from the ISAPRES or the FONASA, but once they opt for the private entities, they are not entitled to get coverage from the National Health Fund. 
In addition to covering formal employees or retirees that have chosen public insurance, the FONASA provides coverage to low-income individuals. The ISAPRES are allowed to negotiate complementary packages with their clients that offer improved access to health services against increased premiums. Because of the higher health risks associated with aging, the ISAPRES discriminate against the elderly, either through prices or by reducing coverage. This explains why most elderly individuals in Santiago (84\% according to SABE estimates) choose public coverage. Only $5 \%$ of older adults had coverage from the ISAPRES in 2000 and 10

The Argentinean healthcare system is divided in three subsystems: public, social security ("Obras Sociales"), and private. The public system provides free access to health services to low-income groups and individuals who lack other coverage. The social security system is a compulsory scheme that covers formal dependent workers and retirees. It is financed by wage contributions that are redistributed across different "Obras Sociales" to ensure increased equality in the provision of care. Retired social security beneficiaries receive coverage from the largest entity in the "Obras Sociales" system: the "Instituto Nacional de Servicios Sociales para Jubilados y Pensionados" (Social Services Administration for Retirees and Pensioners). The private sector is integrated by unregulated private entities that offer voluntary partial or comprehensive insurance to higher income individuals and provide higher quality services. According to data from SABE, in $200051 \%$ of elderly individuals in Buenos Aires were beneficiaries of social security, $21 \%$ reported having public coverage, $10.4 \%$ were covered by private insurance, and $17 \%$ reported no insurance at all. Ten percent of social security beneficiaries had, in addition, complementary private insurance.

In Uruguay the public sector provides health coverage to the low-income population and individuals not covered by other insurance. The main agents in the private sector are the "Instituciones de Asistencia Médica Colectiva" (Institutions of Collective Medical Assistance), private non-profit institutions that act both as insurers and as direct providers of care. These institutions provide coverage to employees contributing to the social security system and sell voluntary insurance (at a regulated premium) to retirees, dependents, and other individuals not formally integrated to the labor market. The private sector includes also for profit health insurers that sell voluntary packages in an unregulated market. Private non-profit insurance covers approximately $45 \%$ of the population, although the rate rises to $60 \%$ when considering elderly adults only. About $38 \%$ of the elderly get coverage from the public system.

A series of equity-enhancing health care policies have been introduced since the administration of SABE in 2000. In Chile, the plan AUGE was introduced to guarantee minimum levels of care to beneficiaries of public and private insurance. Since 2005, health authorities began to explicitly list the package of preventive and curative health services that beneficiaries of all health insurances were entitled to. In addition, the new regulation established maximum time frames for the provision of services, required providers to get accreditation in order to ensure standards of quality, and limited copayments in the ISAPRES and FONASA to $20 \%$ of a nominal value of the service. In 
Uruguay, the government took in 2008 the first steps towards the conformation of a universal social health insurance system (the "Sistema Nacional Integrado de Salud" or National Health Insurance System), aimed at providing equal access to and quality of health care to all the population. The government is gradually incorporating new groups to the scheme. The first groups entitled to the new coverage (in addition to formal workers already contributing to social security) were dependents of formal workers under the age of 18 and low-income retirees. In Argentina, the 2004-2007 Federal Health Plan was designed to strengthen primary care and started by allocating more funds toward promotion and prevention. The Plan considers the gradual, systematic, and organized decentralization of these activities and plans for local governments to take on the implementation of this strategy by developing health promotion policies, providing information, and modeling conduct. Brazil, on its part, has continued consolidating its unique universal and decentralized public health system, based on the conception of health as a right of all citizens.

Most of these reforms are still ongoing. While it is possible that some of the inequities identified in this paper were smoothed out by these policies in the recent years, we believe that our findings are qualitatively up to date and still provide interesting insight for policy makers involved in these reforms.

\section{Data}

The Survey on Health, Wellbeing, and Aging (Encuesta de Salud, Bienestar, y Envejecimiento, SABE, OPS/OMS) was administered in 1999/2000 in seven Latin American and Caribbean cities: Bridgetown (Barbados), Buenos Aires (Argentina), La Habana (Cuba), Mexico DF (Mexico), Montevideo (Uruguay), Santiago de Chile (Chile), and Sao Paulo (Brazil). The study population included individuals aged 60 or more living in private residencies in each of these cities. The survey inquired about a variety of life dimensions, including demographic characteristics, household and housing characteristics, health status, functioning, cognition, mental health, nutrition, use of and access to health services, occupational status, sources of income, and family support. In addition, interviewers obtained anthropometric measures such as weight, height, and some measures of functional status directly from the respondents (see Palloni and Peláez (2009) for a full description of the survey).

Several features make of SABE a unique survey for this study. First, it has an ample variety of indicators of health status, morbidity and chronic diseases, as well as measures of access, use, and quality of health services, providing good inputs for the measurement and decomposition of inequalities in health care. Second, it is one of a few surveys that allows for direct comparisons between different Latin American and Caribbean countries. While its focus on the urban elderly may provide a partial picture of inequalities in each of the referred countries, elderly individuals are the most intensive users of healthcare services. In this respect, the analysis of access to health care by the elderly is likely to shed light on the functioning of the health system as a 
whole.

In this investigation we selected four cities participating in the SABE, all located in the "Southern Cone" of South America: Buenos Aires (Argentina), Montevideo (Uruguay), Santiago (Chile), and Sao Paulo (Brazil). While fairly different from each other, these cities share some cultural and institutional patterns that distinguish them as a block from the other cities in the study.

We defined three categories of measures of access to health services: (i) MD visits and hospitalizations, (ii) quality of the last visit, and (iii) use of preventive care. The first category included dichotomous indicators of any visit to a medical doctor in the past 4 and 12 months, and any hospitalization in the past 12 months. The quality of the (last) visit was assessed by a set of binary indicators that measured if the person had to wait less than a week to get an appointment, if the person spent less than 30 minutes travelling to the doctor's office, if waiting time at the office was less than 30 minutes, whether any examinations were requested at the visit, and whether any medications were prescribed. These measures were only available if the individual had reported at least one medical visit. Finally, the category assessing preventive care included dichotomous indicators of any pap test in the past 2 years (women), any mammogram in the past 2 years (women), any breast examination in the past two years (women), and any prostate examination in the past two years (men).

A problem with $\mathrm{SABE}$ is that it shows a significant number of non-responses and non-trustworthy responses to the questions about household income. Previous studies using SABE and also interested in socioeconomic inequalities have worked with measures of the respondent's education (Noronha and Andrade, 2005) or an index of household durable goods (Wallace and Gutierrez, 2005) as approximations to the respondents' socioeconomic status.

In this study we opted to impute household income from national household surveys also representative of each city and age group in SABE. In the case of Buenos Aires, we used the "Encuesta Permanente de Hogares" (EPH) for 1999-2000, the "Pesquisa Nacional por Amostra de Domícilios (PNAD) 2001" for Sao Paulo, the "Encuesta de Caracterización Socioeconómica" (CASEN) 1999-2000 for Santiago, and for Montevideo the Encuesta Continua de Hogares (Instituto Nacional de Estadistica) 1999-2000. As a first step, we defined, in each of these household surveys, a set of variables associated with income that could be exactly replicated with the SABE data. This set of variables included age, gender, education, occupation, household composition, housing characteristics, durable goods in the household, marital status, and sources of income. Second, we used this data to regress the logarithm of household income on the referred variables (and interactions of these variables) and produced a series of estimated coefficients. Separate regressions were run by gender and city. Income was positively related to the number of people in the household, to being married, to more years of education, to being in the labor force, to being an employer, to owning the house, and to having other sources of income in addition to wage income. The above variables explained approximately half of the variance in the log of income. For Buenos Aires, the regression had an R2 of 0.45 , the R2 equaled 0.58 in the case 
of Sao Paulo, it was 0.48 in Santiago de Chile, and 0.59 in Montevideo. Third, the estimated coefficients were imputed into SABE and a prediction for the logarithm of household income was generated on the basis of the SABE explanatory variables. Imputed income was retransformed into levels using a smearing transformation (Duan, 1983) and converted into equivalent income by dividing its level by the squared root of the total number of people living in the household. While this measure of income may not capture all dimensions of socioeconomic status, it weights a sufficiently comprehensive set of variables to make it more representative of permanent income and household purchasing power than previously used measures such as education or an index of durable goods.

In addition to imputing income, we constructed a set of variables indicative of each individual's need for health care, as well as other determinants of the demand for health care not directly associated with the individual's health status or morbidity (non-need measures). We assessed the need for health care from measures of self-reported health, indicators of chronic conditions, age, gender, and other variables measuring functionality and body mass index. Self-perceived health was defined on the basis of the question: "Would you say your health is excellent, very good, good, fair or poor?" Chronic conditions were identified from the answers to the following questions: "Have you ever been told by a doctor or a health professional that you have any of the following conditions: hypertension, diabetes, cancer, heart disease, lung disease, stroke, arthritis, osteoporosis, or mental health problems?" We also considered among the need variables the respondent's Body Mass Index, the Basic Activities of Daily Living (ADL) scale (a measure of functioning), and indicators of age and gender. While these two variables are not direct measures of morbidity, they capture biologic features associated with the demand for health services that are relatively independent of individual decisions.

We also constructed other control variables that, despite being associated with health care utilization, do not justify the allocation of more health care resources to those with higher levels of these variables. Among these characteristics, we considered health insurance and behavioral health variables such as alcohol consumption, sedentary life, use of tobacco, and diet. Following the literature, we refer to these variables as non-need variables. While alcohol consumption and other unhealthy behaviors may result in a higher demand for health care, this higher demand cannot be justified as "need" from an equity point of view because it stems primarily from individual decisions rather than from biologic factors exogenous to the individual.

Health insurance was captured by three dichotomous variables that indicated if the respondent had public insurance, private insurance, or no insurance coverage, respectively. Risky alcohol behavior took the value of 1 if the individual reported consuming more than 2 drinks per day (more than 1 drink in the case of women) with a frequency of 4 or more days per week; or alternatively, if the individual reported consuming 5 or more drinks (4 or more for women) in average within the same episode. Respondents were considered to have a sedentary life when they did not report exercising at least three times a week in the past 12 months. Tobacco use was captured by a dummy variable 
equal to 1 if the individual was a current smoker (0 otherwise), and a dummy equaling one if the respondent did not currently smoke but had smoked in the past. Finally, a dichotomous variable representing poor diet was set equal to 1 if the individual reported not eating fruits and vegetables on a daily basis (and 0 otherwise).

Variables such as education, housing, marital status, or occupation were not considered as individual controls because they were captured in the imputed measure of income.

Table 1 compares means across the four South American cities for all variables considered in the analysis. Between $74 \%$ and $84 \%$ of the sample population reported visiting a medical doctor in the past 12 months, and between $54 \%$ and $77 \%$ reported having made a visit in the past 4 months. Hospitalization rates in the past 4 months ranged between $4.4 \%$ and $6.2 \%$. Sao Paulo showed the highest prevalence of medical visits and hospitalizations, whereas Santiago showed the lowest.

Table 1. Table of means

\begin{tabular}{|c|c|c|c|c|}
\hline & $\begin{array}{c}\text { Buenos } \\
\text { Aires, } \\
\text { Argentina }\end{array}$ & $\begin{array}{l}\text { Sao Paulo, } \\
\text { Brazil }\end{array}$ & $\begin{array}{l}\text { Santiago, } \\
\text { Chile }\end{array}$ & $\begin{array}{l}\text { Montevideo, } \\
\text { Uruguay }\end{array}$ \\
\hline \multicolumn{5}{|c|}{ Indicators of Access to Health Care } \\
\hline & \multicolumn{4}{|c|}{ MD Visits and Hospitalizations } \\
\hline MD visit past 12 months & 0.825 & 0.843 & 0.738 & 0.76 \\
\hline MD visit past 4 months & 0.699 & 0.774 & 0.536 & 0.713 \\
\hline \multirow{2}{*}{ Hospitalized past 4 months } & 0.055 & 0.062 & 0.044 & 0.061 \\
\hline & \multicolumn{4}{|c|}{ Quality of Care (last appointment) } \\
\hline Time to get appointment $<7$ days & 0.673 & 0.59 & 0.664 & 0.827 \\
\hline Time traveling to appointment $<30 \mathrm{~min}$ & 0.678 & 0.536 & 0.577 & 0.803 \\
\hline Waiting time in office $<30 \mathrm{~min}$ & 0.504 & 0.413 & 0.394 & 0.74 \\
\hline Examinations requested & 0.569 & 0.648 & 0.5 & 0.474 \\
\hline \multirow[t]{2}{*}{ Medications prescribed } & 0.592 & 0.632 & 0.747 & 0.637 \\
\hline & \multicolumn{4}{|c|}{ Use of Preventive Care (past 2 years) } \\
\hline Prostate exam & 0.376 & 0.399 & 0.306 & 0.334 \\
\hline Pap test & 0.344 & 0.381 & 0.308 & 0.249 \\
\hline Mammogram & 0.295 & 0.347 & 0.209 & 0.286 \\
\hline Breast exam & 0.446 & 0.453 & 0.411 & 0.459 \\
\hline \multicolumn{5}{|c|}{ Need variables (Measures of Health Status) } \\
\hline Age & 70.766 & 73.276 & 71.573 & 70.956 \\
\hline Male & 0.369 & 0.411 & 0.343 & 0.366 \\
\hline Self perceived health: excellent or very good & 0.218 & 0.106 & 0.062 & 0.178 \\
\hline Self perceived health: good & 0.444 & 0.342 & 0.293 & 0.454 \\
\hline Self perceived health: fair or poor & 0.339 & 0.552 & 0.645 & 0.368 \\
\hline Body Mass Index & $\mathrm{N} / \mathrm{A}$ & 26.342 & 27.861 & 28.156 \\
\hline
\end{tabular}




\begin{tabular}{|c|c|c|c|c|}
\hline & $\begin{array}{c}\text { Buenos } \\
\text { Aires, } \\
\text { Argentina }\end{array}$ & $\begin{array}{l}\text { Sao Paulo, } \\
\text { Brazil }\end{array}$ & $\begin{array}{l}\text { Santiago, } \\
\text { Chile }\end{array}$ & $\begin{array}{l}\text { Montevideo, } \\
\text { Uruguay }\end{array}$ \\
\hline Lost weight past $12 \mathrm{mnths}$ & 0.201 & 0.279 & 0.337 & 0.204 \\
\hline Hypertension & 0.493 & 0.542 & 0.528 & 0.45 \\
\hline Diabetes & 0.126 & 0.179 & 0.135 & 0.131 \\
\hline Lung disease & 0.085 & 0.126 & 0.128 & 0.092 \\
\hline Heart disease & 0.202 & 0.214 & 0.339 & 0.232 \\
\hline Stroke & 0.047 & 0.08 & 0.069 & 0.04 \\
\hline Arthritis & 0.53 & 0.334 & 0.319 & 0.469 \\
\hline Osteoporosis & 0.296 & 0.318 & 0.354 & 0.289 \\
\hline Mental health problems & 0.121 & 0.144 & 0.256 & 0.161 \\
\hline Basic activities of daily life & 0.833 & 0.785 & 0.765 & 0.857 \\
\hline \multicolumn{5}{|c|}{ Non-need variables } \\
\hline Does not consume fruit and vegetables daily & 0.124 & 0.157 & 0.128 & 0.162 \\
\hline Risky alcohol use & 0.087 & 0.035 & 0.062 & 0.079 \\
\hline Sedentary life & 0.867 & 0.773 & 0.791 & 0.836 \\
\hline Smokes & 0.135 & 0.136 & 0.122 & 0.148 \\
\hline Former smoker & 0.288 & 0.326 & 0.326 & 0.283 \\
\hline Public health insurance & 0.212 & 0.623 & 0.84 & 0.335 \\
\hline Social security health insurance & 0.512 & $\mathrm{n} / \mathrm{a}$ & $\mathrm{n} / \mathrm{a}$ & $\mathrm{n} / \mathrm{a}$ \\
\hline Private health insurance & 0.104 & 0.351 & 0.049 & 0.667 \\
\hline No health insurance & 0.172 & 0.025 & 0.112 & 0.02 \\
\hline \multicolumn{5}{|l|}{ Income } \\
\hline Imputed household income (in 2000 US\$) & 765 & 1203 & 1022 & 1310 \\
\hline \# persons in household & 2.6 & 3 & 3.8 & 2.9 \\
\hline Imputed equivalent income (in 2000 US\$) & 485 & 736 & 469 & 813 \\
\hline $\mathrm{N}$ & 1,039 & 2,143 & 1,301 & 1,444 \\
\hline
\end{tabular}

Montevideo evidenced the best indicators of quality of access to the visit: more than $80 \%$ of respondents who reported having had a visit had obtained the appointment within the week and had spent less than 30 minutes traveling to the clinic or doctor's office. And $74 \%$ of these respondents had waited less than 30 minutes at the doctor's office. Sao Paulo showed the worst indicators of time to get an appointment and transportation to the office: only $59 \%$ of those who reported a visit could get an appointment in less than a week, and $46 \%$ spent more than half an hour travelling to the clinic or doctor's office. Santiago showed the longest waiting times: above $60 \%$ of patients had waited more than 30 minutes at the office or clinic. In terms of examinations requested at the medical visit, Sao Paulo took the lead, with $65 \%$ of patients being recommended a diagnostic examination. Montevideo showed the lowest rate, with only $48 \%$ of patients being recommended an exam. Santiago, on the other hand, showed the highest rate of prescription of medications (75\%) and Buenos Aires the lowest (59\%).

Access to preventive care was low in general in all cities. The best rates 
of use of preventive care were achieved in Sao Paulo, where $40 \%$ of men reported having had a prostate exam in the past 2 years, $38 \%$ of women had had a pap smear, $35 \%$ of women reported having had a mammogram, and $45 \%$ of women reported having had a breast exam in the past 2 years. Santiago showed the worst rates in almost all indicators: only $31 \%$ of men reported a prostate exam, $21 \%$ of women reported a mammogram, and $41 \%$ reported a breast examination. The rate of pap tests was of 31\% in Santiago, lower than in Buenos Aires and Sao Paulo, but higher than in Montevideo (with a rate of only $25 \%$ ).

The mean age in the survey was 72 years old, and around $37 \%$ of respondents were male. Argentinean respondents showed the best levels of self perceived health (followed closely by Uruguayans), whereas Chileans evidenced the highest proportion of individuals reporting fair or poor health. Chileans and Brazilians were more likely than Argentineans and Uruguayans to report health conditions such as hypertension, diabetes, lung disease, heart disease, stroke, osteoporosis, and mental health problems. On the other hand, respondents in Buenos Aires and Montevideo showed poorer dietary habits, higher rates of sedentary life, higher likelihood of alcohol misuse, and higher smoking rates.

In Santiago de Chile, $84 \%$ of respondents had public health insurance, versus $72 \%$ in Buenos Aires, $62 \%$ in Sao Paulo, and only $34 \%$ in Montevideo. Buenos Aires showed the highest rates of uninsured (17\%), followed by Santiago (11\%). Sao Paulo and Montevideo showed low uninsurance rates $(2.5 \%$ and $2.0 \%$ respectively). Household monthly equivalent income measured in 1999/2000 US dollars was of \$ 813 in Montevideo, \$ 736 in Sao Paulo, \$ 485 in Buenos Aires, and \$ 469 in Santiago.

\section{Methodology}

To assess socioeconomic inequality and inequity in access to health care, we followed the standard methodology in the literature (Wagstaff et al., 1989; Wagstaff and van Doorslaer, 2000) and computed concentration indices $\left(I C_{m}\right)$. The concentration index can take up values between -1 and 1 . A value of -1 implies that only the poorest individual has access to healthcare service $\mathrm{m}$, whereas a value of 1 implies that only the richest individual has access to service $m$. A value of 0 would imply that the distribution of access to healthcare service $m$ overlaps with the distribution of income, or that inequalities in favor of the rich in certain parts of the distribution of $m$ are compensated by inequalities in favor of the poor in other parts of the same distribution. In general terms, positive (negative) values of $I C_{m}$ indicate a bias in access to care in favor of those with highest (lowest) socioeconomic status.

Total socioeconomic inequality in care can be decomposed in a series of contributors, which include determinants associated with the need for healthcare services (health status and morbidity), and other enabling and predisposing factors not associated with need. To decompose $I C_{m}$ we first estimated a demand for health service $m$ (a binary indicator of utilization) as a 
probabilistic function of imputed income, need for health care (self perceived health, weight loss, body mass index, self reported chronic diseases, and so forth), and other non-need variables (health insurance and health-related behaviors). As in O'Donnell et al. (2008), we linearly approximated the nonlinear health demand treating the partial effects of need variables, non-need variables, and income as fixed parameters evaluated at the sample mean. Socioeconomic inequality in access to healthcare services $\left(I C_{m}\right)$ can be expressed as the weighted average of the (socioeconomic) inequality in the different need and non-need contributors to the demand for health care, where the weight is defined as the elasticity of healthcare demand to each of these contributors (Rao, 1969; van Doorslaer et al., 2004; Wagstaff et al., 2003). For each measure of access $m$, total socioeconomic inequality was decomposed in: (1) the concentration of income times the elasticity of use of service $m$ with respect to income: (2) socioeconomic inequality in health status or need variables times the elasticity of use of service $m$ with respect to need: (3) socioeconomic inequality in non-need variables (health insurance and health-related behaviors) times the elasticity of use of service $m$ with respect to health insurance and health related behaviors; and (4) a term capturing the unexplained portion of socioeconomic inequality in access to health care.

Horizontal inequity in access to service $m\left(I H_{m}\right)$ was estimated as the difference between total socioeconomic inequality in access to health service $m\left(I H_{m}\right)$ and the contribution of need variables to healthcare inequality (Gravelle, 2003).

We constructed and decomposed the concentration indices for three types of indicators of access in each city: (i) visits and hospitalizations (any medical visits in the past 4 and 12 months and any hospitalization), (ii) quality of the last visit (waiting time between booking and appointment, time travelling to the appointment, waiting time at the office, whether examinations had been requested, and whether medication was prescribed), and (iii) use of preventive care (prostate exam, pap scan test, breast examination, and mammogram). We identified, for each city, the factors that had the greatest incidence in explaining inequality in access to health care, and compared inequity across cities. To assess the statistical significance of the estimated values, standard errors were constructed for each concentration index and its contributors using bootstrapping techniques. ${ }^{2}$

\section{Results}

Tables 2-5 report healthcare concentration indices, contributions of needs, income, behavioral health, and health insurance to socioeconomic inequality, and measures of horizontal inequity for Buenos Aires, Sao Paulo, Santiago and Montevideo, respectively.

As seen in table 2, Buenos Aires (Argentina) did not show any inequality or inequity in access to medical visits or hospitalizations. There was evidence of an unequal distribution of needs for visits and hospitalizations concentrated

${ }^{2}$ Standard errors were constructed based on 400 replications (Stata, 2006). 
among those with lower socioeconomic status, although this inequality in health status did not translate into statistically significant inequities in actual visits or hospital stays. There was also little evidence of inequalities and inequities in the quality of the last visit. Only waiting time in the office showed inequity favoring the rich (those with higher socioeconomic status waited less in the doctor's office), with an index of 0.087 . On the other hand, results revealed strong inequality and inequity favoring the better off in the measures of preventive care. Indices of inequality in prostate exams, pap tests, and breast exams were between 0.11 and 0.12 , and the concentration index for mammograms equaled 0.19. Inequality in preventive care was explained mainly by income inequality (which accounted for more than $60 \%$ of overall concentration) and by pro rich inequalities in health insurance (which explained about $30 \%$ of inequalities in preventive care). Horizontal inequity was of 0.123 in the case of prostate exams, 0.113 in the case of pap tests, 0.175 for mammograms, and 0.094 for breast exams. All residuals showed negative signs, suggesting a failure to capture unobserved needs for care (usually pro poor) and potentially higher inequity in preventive care. 


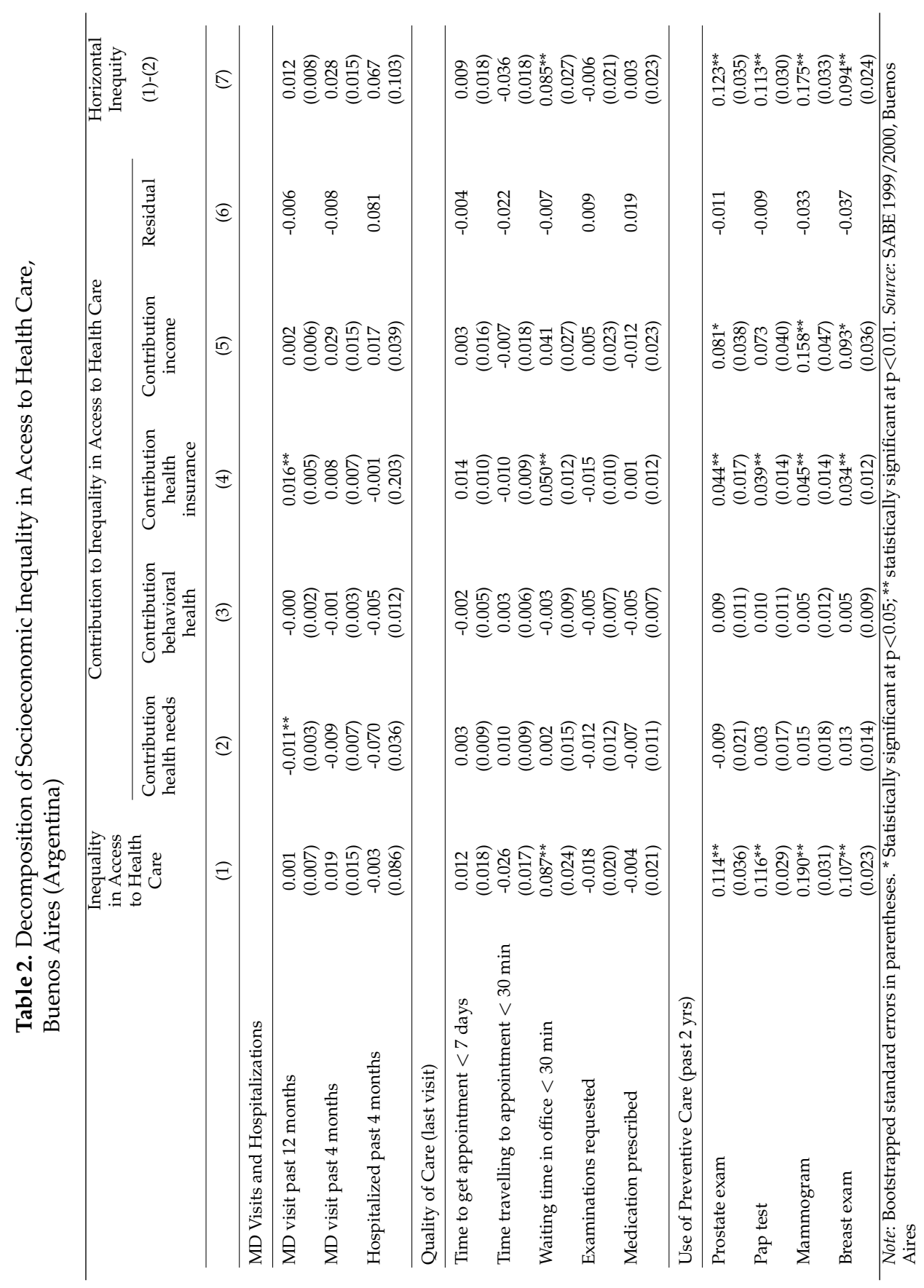


Table 3 shows concentration indices, contributions to inequality, and measures of horizontal inequity for Sao Paulo (Brazil). In this city, needs for medical visits and hospitalizations were unequally distributed in favor of the poorest and health insurance contributed positively to inequalities in access to MD visits. However, there was no statistically significant evidence (at $\mathrm{p}<0.05$ ) of horizontal inequity in these measures of utilization. Unlike Buenos Aires, Sao Paulo showed pro rich inequalities and inequities in most indicators of the quality of a visit. Horizontal inequity in the time to get an appointment attained a value of 0.046 , mostly due to the contribution of income inequality. Requests of examinations showed an index of horizontal inequity of 0.059, and waiting time in the office evidenced the highest pro rich inequity, with an index of 0.104 . The pro rich inequities in these two cases were mostly due to the unequal socioeconomic distribution of health insurance and to the concentration of income. The strongest magnitudes of horizontal inequity were found for measures of preventive care. The inequity index for prostate exams equaled 0.129; it attained a value of 0.083 for pap tests; it was 0.128 in the case of mammograms; and 0.095 for breast exams. The pro rich distribution of health insurance was the main contributor to the observed inequities. 


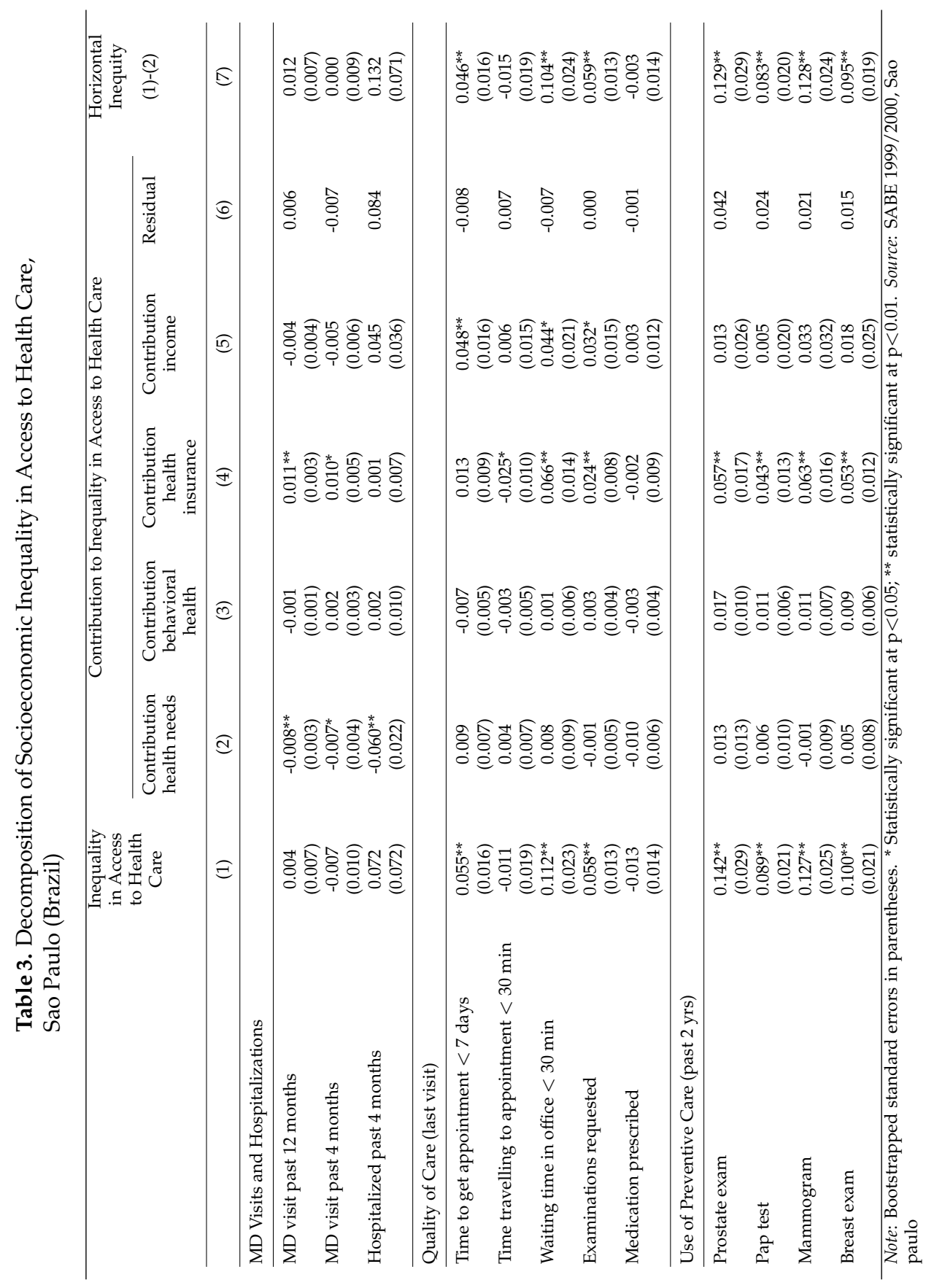


Santiago de Chile (table 4) showed horizontal inequity favoring the rich in access to medical visits in the past 4 months (the inequity index equaled 0.046) and horizontal inequity favoring the poor (at $p<0.10$ ) in the case of hospitalizations. Income inequality was the main contributor to these values. In the case of medical visits, those with higher income were more likely to have a visit, and income inequality contributed positively to horizontal inequity in MD visits. Regarding hospitalizations, those with lower income were more likely to be hospitalized, and income inequality contributed negatively to total inequality in hospitalizations (with a pro poor concentration). Again, a failure to adequately control for morbidity or healthcare needs could be explaining the negative sign on hospitalizations. The big magnitude and sign of the residual in the analysis of hospitalizations is suggestive of underlying unobserved need factors associated both with income and hospitalizations. Informal evidence for these countries suggests that poor patients are, all else equal, more likely to be hospitalized because they are less likely to have adequate conditions for care and recovery at home. If such is the case, and this need is not captured in the observed indicators, the income contribution will reflect part of the effect. In terms of the quality of visits, Santiago showed pro rich horizontal inequity in the likelihood of getting an appointment in less than a week (0.057), and in the likelihood of waiting in the office for less than 30 minutes (0.081). In both cases, the concentration of income was the main contributor to these inequities. Regarding preventive care, Santiago showed pro rich horizontal inequities in access to prostate exams (0.118) and in access to mammograms (0.094). Income inequalities explained most of the concentration in the former service, whereas inequity in mammograms was due to the pro rich contribution of income and health insurance, and to the unequal concentration of needs for the exam among the poor. 


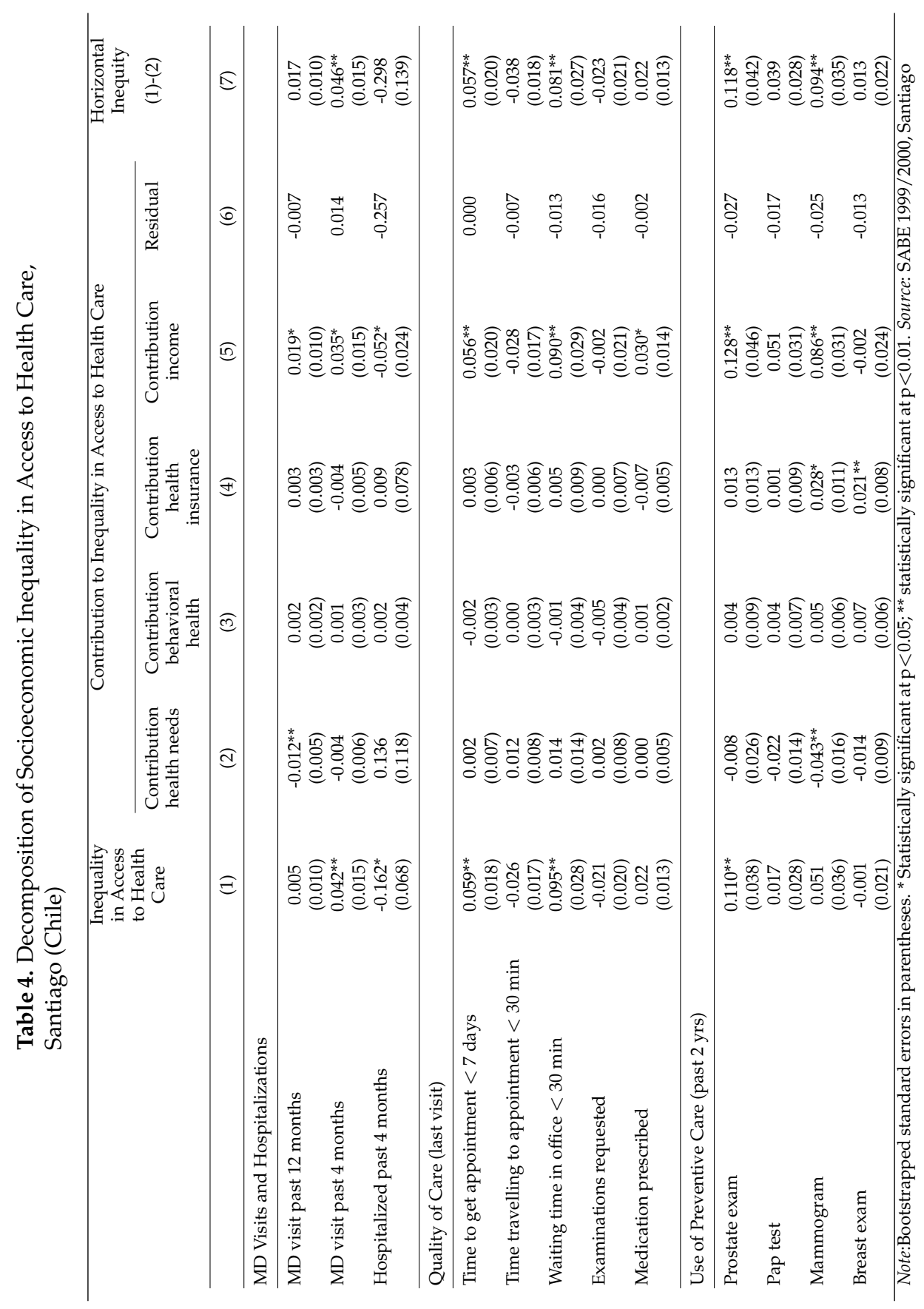


Table 5 presents findings for Montevideo (Uruguay). MD visits were unequally distributed in favor of the rich in this city, with a horizontal inequity index of 0.041 for visits in the past 12 months and 0.038 for visits in the past 4 months. In both cases, inequity was explained by a higher concentration of health needs among the poor and a higher concentration of income among the rich. Interestingly, two measures of the quality of visits showed horizontal inequities in favor of the poor. After adjusting for needs, those with lower socioeconomic status were more likely to get appointments in less than a week (horizontal inequity equaled -0.039) and more likely to be prescribed medication (the level of inequity was of -0.035). In the first case, most of the observed inequity stemmed from a negative contribution of income inequality, whereas in the second, it was mostly explained by the negative contribution of health insurance. It is quite possible that these negative indices reflect, again, unobserved determinants related to need for health care. Low income individuals with a poor healthcare coverage are more likely to delay care and to make a consultation at the emergency. Some of the reported "visits" may have occurred at the emergency room explaining why it took less time for poor people to see a medical doctor. Furthermore, if lower income individuals are more likely to delay care, they may be more severe once they show up at the clinic. This would explain why poor individuals are more likely to be prescribed medication at the medical visit. As in the other cities, the highest pro rich horizontal inequities in Montevideo were observed for preventive services. The index of horizontal inequity for prostate exams attained a value of 0.205 ; it was 0.168 for pap tests; 0.127 for mammograms; and 0.047 for breast exams. The main determinant of these inequities was the concentration of income. 


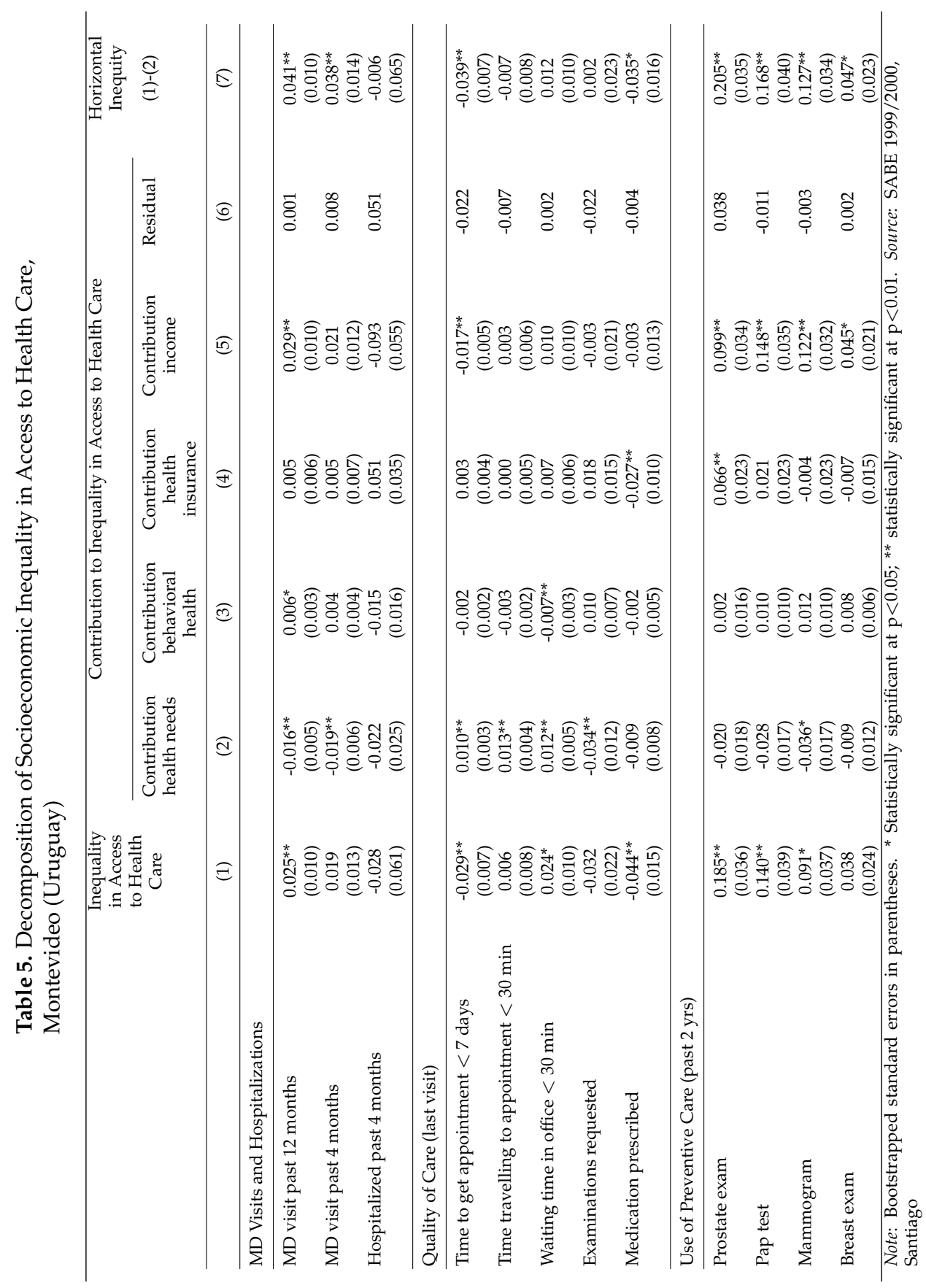


Table 6 summarizes, for ease of comparison, horizontal inequities in all measures of access for the four cities analyzed. Only Santiago and Montevideo presented inequities in medical visits favoring those with higher status. Findings for Sao Paulo showed some evidence (statistically significant at $\mathrm{p}$ i 0.10) of pro rich inequities in hospitalizations, whereas in Santiago there was evidence of pro poor inequities in hospital stays. In terms of quality indicators, results for Sao Paulo and Santiago revealed pro rich inequities in the time required to get an appointment; and all cities but Montevideo presented pro rich inequities in the time waiting at the office (horizontal inequities ranging between 0.08 and 0.10 in all three cities). Sao Paulo also showed inequities in favor of the better off in examinations requested, whereas Montevideo presented pro poor inequities in the time to get an appointment and medication prescribed. The strongest commonality across the cities was in access to preventive care. All cities showed strong and statistically significant pro rich inequities in access to prostate exams and mammograms, and almost all locations except Santiago evidenced, in addition, inequities in pap smears and breast exams. The highest level of inequity was observed in Montevideo for prostate exams, with a horizontal inequity index of 0.205 , versus approximately 0.12 in the other cities. Montevideo depicted also the highest inequities in pap smears (0.168 versus 0.113 in Buenos Aires and 0.083 in Sao Paulo). Inequities in breast examinations, on the other hand, were higher in Buenos Aires and San Pablo with an index of 0.10.

A question of interest is whether policy makers in these countries are trading off increases in inequality against improvements in the mean of the distribution. We did not find evidence of a trade off between the levels of access to services and the income concentration of these services. On the contrary, those cities scoring low in terms of levels of access or quality, presented in many cases the strongest inequities in those measures. Santiago depicted the lowest levels of access to MD visits and also the highest inequity. Similarly, Sao Paulo showed the highest rate of patients having to wait more than a week to get an appointment, and one of the highest concentrations in this measure (after Santiago). The likelihood of waiting more than 30 minutes at the doctor's office or clinic was also higher in both Santiago and Sao Paulo (compared to Buenos Aires and Montevideo), and both cities showed strong horizontal inequities in this indicator of quality. Montevideo, on the other hand, scored well both on the level and equity dimensions of the quality of visit indicators (time between booking and appointment, transportation time, and waiting time at the clinic or office). On the other hand, Montevideo showed the lowest levels of access to pap tests, a low level of access to prostate exams, and the highest inequities in these measures. Only for Santiago, there was some evidence of a trade off between levels of access to preventive services and inequality in these services. Santiago showed the lowest rates of access to most preventive services but the lowest levels of inequities in access to these services when compared to the other cities.

There are some limitations to the analysis. The decomposition of inequality did not consider the potential endogeneity between access to health care, and explanatory variables such as need for health care, health insurance, and 
Table 6. Summary Table. International Comparison of Socioeconomic Inequities in Access to Health Care

\begin{tabular}{|c|c|c|c|c|}
\hline & $\begin{array}{c}\text { Buenos } \\
\text { Aires, } \\
\text { Argentina }\end{array}$ & $\begin{array}{c}\text { Sao Paulo, } \\
\text { Brazil }\end{array}$ & $\begin{array}{l}\text { Santiago, } \\
\text { Chile }\end{array}$ & $\begin{array}{l}\text { Montevideo, } \\
\text { Uruguay }\end{array}$ \\
\hline & $(1)$ & $(2)$ & (3) & $(4)$ \\
\hline \multicolumn{5}{|l|}{ MD Visits and Hospitalizations } \\
\hline MD visit past 12 months & $\begin{array}{c}0.012 \\
(0.008)\end{array}$ & $\begin{array}{c}0.012 \\
(0.007)\end{array}$ & $\begin{array}{c}0.017 \\
(0.010)\end{array}$ & $\begin{array}{l}0.041^{* *} \\
(0.010)\end{array}$ \\
\hline MD visit past 4 months & $\begin{array}{c}0.028 \\
(0.015)\end{array}$ & $\begin{array}{c}0.000 \\
(0.009)\end{array}$ & $\begin{array}{l}0.046^{* *} \\
(0.015)\end{array}$ & $\begin{array}{l}0.038^{* *} \\
(0.014)\end{array}$ \\
\hline Hospitalized past 4 months & $\begin{array}{c}0.067 \\
(0.103)\end{array}$ & $\begin{array}{c}0.132 \\
(0.071)\end{array}$ & $\begin{array}{l}-0.298 \\
(0.139)\end{array}$ & $\begin{array}{l}-0.006 \\
(0.065)\end{array}$ \\
\hline \multicolumn{5}{|l|}{ Quality of Care (last visit) } \\
\hline Time to get appointment $<7$ days & $\begin{array}{c}0.009 \\
(0.018)\end{array}$ & $\begin{array}{l}0.046^{* *} \\
(0.016)\end{array}$ & $\begin{array}{l}0.057^{* *} \\
(0.020)\end{array}$ & $\begin{array}{c}-0.039^{* *} \\
(0.007)\end{array}$ \\
\hline Time travelling to appointment $<30 \mathrm{~min}$ & $\begin{array}{l}-0.036 \\
(0.018)\end{array}$ & $\begin{array}{l}-0.015 \\
(0.019)\end{array}$ & $\begin{array}{l}-0.038 \\
(0.018)\end{array}$ & $\begin{array}{l}-0.007 \\
(0.008)\end{array}$ \\
\hline Waiting time in office $<30 \mathrm{~min}$ & $\begin{array}{l}0.085^{* *} \\
(0.027)\end{array}$ & $\begin{array}{l}0.104^{* *} \\
(0.024)\end{array}$ & $\begin{array}{l}0.081^{* *} \\
(0.027)\end{array}$ & $\begin{array}{c}0.012 \\
(0.010)\end{array}$ \\
\hline Examinations requested & $\begin{array}{l}-0.006 \\
(0.021)\end{array}$ & $\begin{array}{l}0.059^{* *} \\
(0.013)\end{array}$ & $\begin{array}{l}-0.023 \\
(0.021)\end{array}$ & $\begin{array}{c}0.002 \\
(0.023)\end{array}$ \\
\hline Medication prescribed & $\begin{array}{c}0.003 \\
(0.023) \\
\end{array}$ & $\begin{array}{l}-0.003 \\
(0.014)\end{array}$ & $\begin{array}{c}0.022 \\
(0.013) \\
\end{array}$ & $\begin{array}{l}-0.035^{*} \\
(0.016)\end{array}$ \\
\hline \multicolumn{5}{|l|}{ Use of Preventive Services (past 2 yrs) } \\
\hline Prostate exam & $\begin{array}{l}0.123^{* *} \\
(0.035)\end{array}$ & $\begin{array}{l}0.129^{* *} \\
(0.029)\end{array}$ & $\begin{array}{l}0.118^{* *} \\
(0.042)\end{array}$ & $\begin{array}{l}0.205^{* *} \\
(0.035)\end{array}$ \\
\hline Pap test & $\begin{array}{l}0.113^{* *} \\
(0.030)\end{array}$ & $\begin{array}{l}0.083^{* *} \\
(0.020)\end{array}$ & $\begin{array}{c}0.039 \\
(0.028)\end{array}$ & $\begin{array}{l}0.168^{* *} \\
(0.040)\end{array}$ \\
\hline Mammogram & $\begin{array}{l}0.175^{* *} \\
(0.033)\end{array}$ & $\begin{array}{l}0.128^{* *} \\
(0.024)\end{array}$ & $\begin{array}{l}0.094^{* *} \\
(0.035)\end{array}$ & $\begin{array}{l}0.127^{* *} \\
(0.034)\end{array}$ \\
\hline Breast exam & $\begin{array}{l}0.094^{* *} \\
(0.024)\end{array}$ & $\begin{array}{l}0.095^{* *} \\
(0.019)\end{array}$ & $\begin{array}{c}0.013 \\
(0.022)\end{array}$ & $\begin{array}{l}0.047^{*} \\
(0.023)\end{array}$ \\
\hline
\end{tabular}

Note: Bootstrapped standard errors in parentheses. * Statistically significant at $\mathrm{p}_{i} 0.05 ;{ }^{* *}$ statistically significant at $\mathrm{p}_{i} 0.01$.

Data source: SABE 1999/2000.

income. First, access to health care and need for health care may be endogenously determined because they were measured simultaneously in the survey. Because using health services improves health, reported health status may depend on the use of health services. Moreover, some conditions are more likely to be detected when the respondent has been in contact with the healthcare system. Second, failure to include all relevant measures of need could also result in biases if these unobserved measures were correlated with other ex- 
planatory variables such as income or health insurance. In fact, we suspect that some of the negative concentration indices identified could well reflect the omission of need variables in the regression. Third, health insurance is usually not exogenous to (observed and unobserved) measures of health status: individuals with more severe health conditions are likely to select into more comprehensive insurances and are likely to use services differently. Finally, the simultaneity between income and health introduces another source of endogeneity. It is unclear whether health (and health care) are determined by income or if good health (due in part to access to health care) is the cause for a satisfactory socioeconomic status. While no causality should be interpreted from our findings, we still believe that many of these problems affect our results by biasing downwards the estimates, and our estimates reflect, at least, lower bounds to actual levels of pro-rich inequality.

\section{Conclusions}

This paper is one of a few studies to use concentration indices and decomposition methods to quantify and explain socioeconomic inequalities and inequities in access to health care in South America (Buenos Aires, Santiago, Sao Paulo, and Montevideo).

We found horizontal inequities in MD visits in Montevideo and Santiago, but not in Sao Paulo or Buenos Aires. Results also showed that rationing mechanisms (such as waiting days for an appointment, or waiting time at the office) affected primarily those with lower socioeconomic status in all cities but Montevideo. Finally, access to preventive services was distributed inequitably in all cities and achieved the highest inequity magnitudes when compared to other healthcare services.

The decomposition of inequalities in access to health care suggests that inequities in these South American cities are not always related to the fragmentation of health insurance. While inequities in Sao Paulo stemmed primarily from differences in access between the privately and publicly insured, in the other cities income inequality was the main contributor to inequity in access, after adjusting for the type of health insurance. The lack of significance of health insurance when it came to explaining inequities was expected in the case of Chile, where most of the elderly are covered by public insurance. But the finding was quite surprising in the case of Uruguay, with a heavily fragmented system and important resource differences between the private and public sectors. In Argentina, health insurance contributed to explain inequities in waiting times and preventive services, but its contribution was much smaller than that of income inequality. In sum, our results for all cities but Sao Paulo, suggest that inequities within each health system (public or private) are more important than between systems. Within the private insurance system, disparities in use and quality of access may be explained by the existence of differential premiums, out of pocket charges, or copayments that operate as barriers to care. For example, in Uruguay, copayments in the private system have operated as a strong barrier to care among elderly adults, 
and may be explaining part of the inequities in access to healthcare (Balsa et al 2009). Among beneficiaries of public systems, on the other hand, where financial charges are less of an issue, higher socioeconomic status may be associated with a better ability to "navigate" the system (finding ways to avoid queues and delays in access) or with better information on how to use services. In this sense, we believe that the strong inequities detected in access to preventive services for all cities are less likely to be the result of out of pocket costs or copayments (which operate mainly at the private level), than of information and educational gaps between individuals of different socioeconomic status.

Beyond health insurance and income inequality, the unequal distribution of need for health care was another reason for the observed inequities in medical visits in Montevideo and Santiago. Brazil and Argentina also evidenced pro-poor distributions in the need for hospital stays.

Our findings provide insights into how South American health systems and income inequalities interact in the determination of healthcare inequities. Our results are particularly informative in the context of the reform processes that several of these Latin American countries are undertaking. Our results regarding preventive services and quality of care are relevant given new regulations specifying the minimum types of services that providers should offer ("Plan Integral de Atención a la Salud (PIAS) in Uruguay, or "Plan Auge" in Chile). Because most of these regulatory processes are still ongoing, our findings can shed light on the types of services and sources of inequities that need more serious attention. In addition, our results highlight the need to address sources of inequality within each health sub-system. Reform efforts exclusively aimed at defragmenting the system could have limited success in reducing inequalities.

\section{References}

Bertranou, F. (1993). Demanda por consultas preventivas de salud: aplicación de un modelo logit al caso del gran mendoza. CDI-MECON Reunión Anual 28 .

Bertranou, F. (1998). Health care services utilization and health insurance coverage: Evidence from argentina. Revista de Análisis Econónico 13(2), 25-52.

Bertranou, F. (1999). Are market-oriented health insurance reforms possible in latin america?: The cases of argentina, chile and colombia. Health Policy $47(1), 19-36$.

Culyer, A. and J. Newhouse (2003). Handbook of health economics. 1(B).

De Santis, M. and V. Herrero (2009). Equidad en el acceso, desigualdad y utilización de los servicios de salud. una aplicación al caso argentino en 2001. Revista de Economía y Estadística XLVII(1), 125-162. 
Duan, N. (1983, September). Smearing estimate: A nonparametric retransformation method. Journal of the American Statistical Association 78(383), 605610.

García Gómez, P. and N. López (2004, April). The evolution of inequity in access to health care in spain:1987-2001. Departamento de Economía, Universidad Pompeu Fabra.

Gravelle, H. (2003). Measuring income related inequality in health: standardization and the partial concentration index. Health Economics 12(10), 803819.

Macinko, J. and B. Starfield (2002). Annotated bibliography on equity in health, 1980 - 2001. International Journal for Equity in Health 1(1), 1-20.

Noronha, K. and M. Andrade (2005). Desigualdades sociais em saúde e na utilizaçao dos serviços de saúde entre os idosos na américa latina. Revista Panamericana de Salud Pública 17(5/6), 410-418.

O'Donnell, O., E. van Doorslaer, A. Wagstaff, and M. Lindelow (2008). Analyzing health equity using household survey data: A guide to techniques and their implementation. WBI Learning Resources Series. The International Bank for Reconstruction and Development/ The World Bank, Washington, DC.

PAHO (2002). Investment in health: social and economic returns. Revista Panamericana de Salud 12, 140 - 141.

Palloni, A. and M. Peláez (2009). Survey on health and wellbeing of elderls. Pan American Health Organization; Washington DC. Final Report.

Rao, V. M. (1969). Two decompositions of concentration ratio. Journal of the Royal Statistical Society. Series A (General) 132(3), 418-425.

Stata (2006). Stata statistical software: Release 9.1. College Station, TX: StataCorp LP.

Suárez Berenfuela, R. (2000). Health system inequalities and inequities in latin america and the caribbean: Findings and policy implications. Working Document prepared for the Health and Human Development Division of the Pan American Health Organization-World Health Organization. World Bank EquiLAC Project, Investments in Health Equity and Poverty Project.

van Doorslaer, E., X. Koolman, and A. Jones (2004). Explaining income-related inequalities in doctor utilisation in europe. Health Economics 13(7), 629-647.

van Doorslaer, E., C. Masseria, and X. Koolman (2006, January). Inequalities in access to medical care by income in developed countries. Canadian Medical Association Journal 174(2), 177-183.

Wagstaff, A. and E. van Doorslaer (2000). Measuring and testing for inequity in the delivery of health care. The Journal of Human Resources 35(4), 716-733. 
Wagstaff, A., E. van Doorslaer, and P. Paci (1989, Spring). Equity in the finance and delivery of health care: Some tentative cross-country comparisons. $O x$ ford Review of Economic Policy 5(1), 89-112.

Wagstaff, A., E. van Doorslaer, and N. Watanabe (2003, January). On decomposing the causes of health sector inequalities with an application to malnutrition inequalities in vietnam. Journal of Econometrics 112(1), 207-223.

Wallace, S. and V. Gutierrez (2005). Equity of access to health care for older adults in four major latin american cities. Revista Panamericana de Salud Pública 17(5/6), 394-409. 